\title{
Review of VSC HVDC Connection for Offshore Wind Power Integration
}

\author{
Korompili, Asimenia; Wu, Qiuwei; Zhao, Haoran
}

Published in:

Renewable \& Sustainable Energy Reviews

Link to article, DOI:

10.1016/j.rser.2016.01.064

Publication date:

2016

Document Version

Peer reviewed version

Link back to DTU Orbit

Citation (APA):

Korompili, A., Wu, Q., \& Zhao, H. (2016). Review of VSC HVDC Connection for Offshore Wind Power Integration. Renewable \& Sustainable Energy Reviews, 59, 1405-1414.

https://doi.org/10.1016/j.rser.2016.01.064

\section{General rights}

Copyright and moral rights for the publications made accessible in the public portal are retained by the authors and/or other copyright owners and it is a condition of accessing publications that users recognise and abide by the legal requirements associated with these rights.

- Users may download and print one copy of any publication from the public portal for the purpose of private study or research.

- You may not further distribute the material or use it for any profit-making activity or commercial gain

- You may freely distribute the URL identifying the publication in the public portal

If you believe that this document breaches copyright please contact us providing details, and we will remove access to the work immediately and investigate your claim 


\title{
Review of VSC HVDC Connection for Offshore Wind Power Integration
}

Asimenia Korompili, ${ }^{\mathrm{a}, \mathrm{b}}$, Qiuwei $\mathrm{Wu}^{\mathrm{a}, *}$, Haoran Zhao ${ }^{\mathrm{a}}$

a. Centre for Electric Power and Energy, Department of Electrical Engineering, Technical University of Denmark (DTU), Elektrovej 325, Kgs. Lyngby, DK-2800

b. Institute for Automation of Complex Power Systems, E.ON Energy Research Center, RWTH Aachen University, Mathieustraße 10, Germany

\begin{abstract}
Voltage Source Converter (VSC) High Voltage Direct Current (HVDC) connection has become a new trend for long distance offshore wind power transmission. It has been confirmed by a lot of research that the maximum distance of a High Voltage Alternative Current (HVAC) sub-marine cable transmission system is limited due to surplus charging current of the cables. The VSC HVDC transmission system has the ability to overcome the limitation and offers other advantages over the HVAC transmission system. This paper is to review the VSC HVDC transmission technology and its application for offshore wind power integration. Firstly, the main components, configuration and topology of the VSC HVDC transmission system are described. Secondly, the converter control system and control strategies are presented. Following that, the capabilities of the VSC HVDC technology are described. Finally, the focus is given on the control methods of the VSC HVDC transmission system for fulfilling grid code requirements concerning Low Voltage Ride-Through (LVRT) and frequency regulation.
\end{abstract}

Keywords: Converter control system, offshore wind farms, voltage source converter, VSC HVDC transmission system, wind power integration

\section{Introduction}

Nowadays, concern about the global climate change is increasing. In order to reduce the Greenhouse Gas (GHG) emission and limit the global warming, Renewable Energy Sources (RESs) like wind and solar energy have gained worldwide attention.

Due to the wide distribution of potential large-scale wind sources all over the world and technology maturity, wind energy is the most exploited RES. Although most of the wind power is 
nowadays produced by onshore wind turbines, offshore wind farms have been of high interest, mainly due to the huge unexploited wind resources and the better wind conditions at offshore locations. In the future, the capacity of the offshore wind farms is going to increase, as well as their distance from the shore. Therefore, there is a clear need to investigate the power transmission technologies for connecting large offshore wind farms located at a long distance to the nearby in-land network. In recent years, various transmission options have been analyzed and investigated in terms of their technical and economic feasibility of connecting large offshore wind farms to the in-land power grid, as well as their effect on the stability of the connected power system [1-10].

High Voltage Alternative Current (HVAC) technology offers a simple and cost-efficient solution for bulk power transmission and reliable integration of large-scale RESs. Consequently, most of the present large offshore wind farms are grid-connected through such transmission systems [8,11]. However, a HVAC system has bottlenecks, mainly concerning the increase of power losses and cost with the transmission distance, as well as requirements for reactive power compensation. Therefore, the HVAC transmission systems for the grid connection of large and remote offshore wind farms are, in most cases, not preferred [6,7,10,12,13].

Consequently, High Voltage Direct Current (HVDC) transmission technology has become an interesting alternative because DC systems offer more attractive solutions for power transfer over long distances $[6-8,10,12-15]$. HVDC transmission systems are either based on Current Source Converters (CSCs) [5,16,17], also called Line Commutated Converters (LCC), or Voltage Source Converters (VSCs) [15,18-21]. Since its first commercial application, the LCC HVDC system has been evolved; new components have been developed and additional structures have been proposed to improve the power quality [19-26]. The comparatively new VSC HVDC transmission system has become possible with the development of Insulated-Gate Bipolar Transistors (IGBTS). The advanced controllability of the VSC HVDC technology has rendered the power transmission system capable of providing grid support to the connected AC networks [8-10,15,17,27,28]. Therefore, VSC HVDC transmission systems have experienced an increasingly wider range of applications [14,15,27,29-33]. One of the emerging application areas is the integration of remote RESs to the power system. The advantages of the VSC HVDC transmission technology make it more suitable than other transmission systems (HVAC, CSC-HVDC) for the grid connection of offshore wind farms $[1,10]$. The system configuration of a VSC HVDC connection for an offshore wind farm is illustrated in Figure 1 [10].

This paper presents a review of the VSC HVDC transmission technology and latest development of its application for offshore wind power integration. It aims to introduce the technical features of the VSC HVDC technology, describe the capabilities of the VSC HVDC system to improve offshore wind power integration and provide grid support, and present the relevant control strategies. The paper is organized as follows: In Section 2, the main components of the VSC HVDC transmission system, as well as various configurations and topologies, are described. Section 3 analyses the control system of the VSC and the control 
strategies. The capabilities of the VSC HVDC transmission system for grid support are presented in Section 4. The grid code requirements for offshore wind farms and VSC HVDC systems are briefly discussed in Section 5. Control methods for Low Voltage Ride-Through (LVRT) and frequency regulation are given in Sections 6 and 7, respectively. A conclusion is drawn in the end.

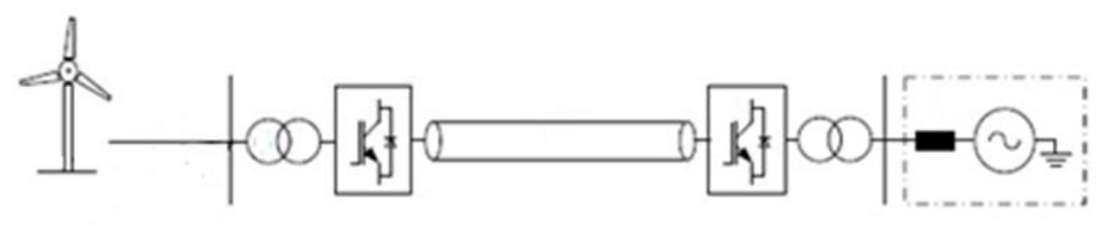

Figure 1: Grid connection of offshore wind farm through VSC HVDC transmission system

\section{VSC HVDC transmission systems}

This section describes the main components, configuration and topology of the VSC HVDC transmission system.

\subsection{Components of the VSC HVDC transmission systems}

A typical VSC HVDC transmission system is comprised of converters, transformers and phase reactors, AC filters, DC cables and breakers, and DC capacitors and filters, as illustrated in Figure 2 [34]. Transformers, filters and auxiliary capacitors are located outdoors. The converter and its control system are placed in a closed air-conditioned and air-heated building. The VSC HVDC system allows compact stations, suitable for locations where the space is a concern due to restrictions regarding environmental impact, scarcity of land or economic reasons $[6,35]$. The role and structure of each component are briefly described in the following subsections.

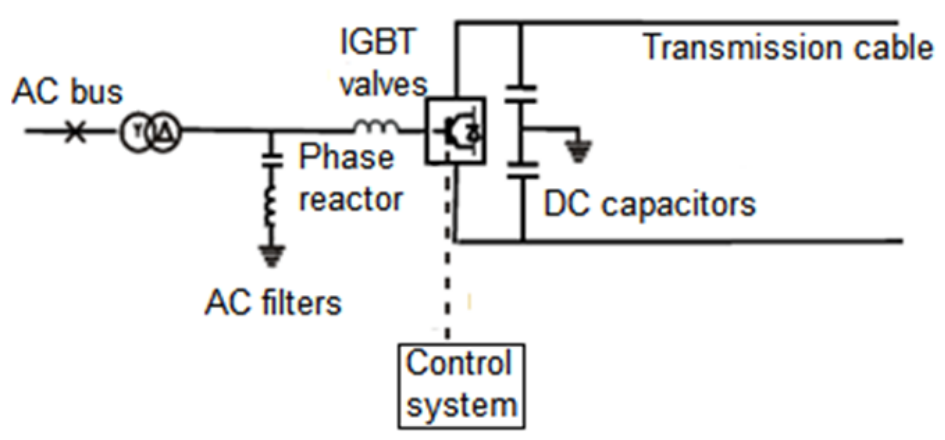

Figure 2: VSC HVDC transmission system

\subsubsection{Converter}

The converter is the most important module, since it performs the conversion from $A C$ to $D C$ (rectification) at the sending end and from $D C$ to $A C$ (inversion) at the receiving end of the DC link. The three-phase AC voltage is converted to a symmetrical DC voltage, which is considered 
constant, with fixed polarity. By allowing control of turn-on and turn-off operation, the IGBT valves can compose Self-Commutated Converters (SCCs). Hence, the operation of the converter does not rely on synchronous machines in the connected AC system, which could be a totally passive network. This is impossible in the case of LCCs based on Thyristors $[2,19]$. IGBTs are switched on and off with frequencies defined by Pulse-Width Modulation (PWM) algorithms. In this way, the PWM can create any desired voltage waveform, meaning any phase angle and magnitude of the fundamental frequency component $[2,17,19,21]$. However, due to the switching process of IGBTs, the AC output currents and voltages are not sinusoidal, i.e. the spectrum of their waveforms contains not only the fundamental frequency component $f_{1}$, but also higher-order harmonics. This harmonic content consists of components around the carrier frequency $f_{c}$ of the PWM and its multiples. The higher the number of IGBT commutations per second, the higher the frequency of the lowest-order harmonics produced, meaning reduced harmonic losses. On the other hand, the higher the number of commutations per second, the higher the switching losses. Therefore, the frequency modulation ratio in the PWM process should be selected properly, to strike a balance between switching and harmonic losses $[2,17,19]$. Several other modulation methods have been proposed in literature, such as the Space Vector Modulation (SVM) [36] and the Tolerance Band Modulation (TBM) [37], to reduce the switching losses.

For achieving large converter ratings, series-connected valves are arranged in either a twolevel or three-level bridge. The two-level converter is the simplest configuration, consisting of a 6-pulse bridge, which generates a discrete, two-level output voltage $\left(+U_{d} / 2,-U_{d} / 2\right.$, where $U_{d}$ is the DC voltage). For keeping the current ripple relatively low, the switching frequency must be chosen comparatively high, resulting in high switching losses. Therefore, this configuration presents the highest harmonic distortion and highest converter losses among all the VSC topologies $[2,17,21,38]$. By clamping the neutral point of the DC link, a three-level converter is constructed, providing three different levels of the voltage output at each phase $\left(+U_{d} / 2,0\right.$, $-U_{d} / 2$, where $U_{d}$ is the DC voltage). The resulted voltage resembles much more ideal sinusoidal waveform than that of the two-level converter. This implies less harmonic distortion and therefore less filtering is required [4,17].

For increasing the number of voltage levels and thus generating a better waveform (closer to sinusoidal), a strictly modular construction is needed, by cascading the same hardware, namely the same module. Various cascaded converter topologies have been suggested [39-42]. Recently, a new multi-level converter topology has been developed, called Modular Multi-level Converter (MMC). This configuration is able to synthesize a stepped voltage with a large number of small steps. This means reduced voltage gradients, and consequently very low harmonic distortion. As a result, less passive and active filters are required, which are mandatory in a two-level or three-level converter, due to the high and steep steps of their voltage output. Despite the high frequency of the final waveform, the switching frequency of 
each module can be low, resulting in reduced switching losses, since the number of switching devices is large and each of them does not have to operate frequently. In general, MMC systems present easy scalability, leading to high power ratings, and high modularity, allowing more flexible and economical solutions for the transmission systems $[2,4,9,10,38,43,44]$.

\subsubsection{Transformers and phase reactors}

The three single-phase transformers transform the voltage of the AC bus to the required entry voltage of the converter. For ensuring the correct valve voltage, the transformers are equipped with tap-changers. Their design is usually simple and conventional, due to lower harmonic content of the current in the VSC HVDC scheme [2,17].

The aim of the single-phase air-cooled reactors is to control active and reactive power flow, by regulating currents through them. They are also used as filters, for reducing high-frequency harmonics of the AC current, caused by the switching operation of the converter $[17,19]$.

\subsubsection{AC filters}

The high-order harmonics of $A C$ output currents and voltages have to be mitigated to prevent their emission into the AC system, since they could cause malfunction of $A C$ equipment or radio and telecommunication disturbances $[2,5,17]$. For this purpose, passive or active highpass filters are installed in the transmission system, providing the AC system with almost sinusoidal currents and voltages $[20,23,25,26]$. However, the low harmonic distortion and the need of no reactive power compensation allow the small size and simple type of the filters $[2,17,19]$.

\subsubsection{DC cables and breakers}

The DC transmission circuit consists of the DC links, the high-speed DC switches and the earth electrode. Regarding the DC cable types, new technologies have been developed, since the current underground cables were found to be heavy, difficult to install and prone to faults. The new cable types has better insulation and lower power losses, lightweight design and flexibility, leading to more applications, as submarine or overhead links [45-49].

Concerning the DC breakers, instead of mechanical DC switches, which are quite slow, or electronic DC switches, which are faster but more expensive [50], a new generation has been proposed, known as hybrid DC breakers. The new type has been found to be fast, efficient and reliable. Moreover, the modular design makes it easily adapted to actual voltage and current ratings [51-53].

\subsubsection{DC capacitors and filters}

For reducing the DC voltage ripple caused by the switching process in the IGBTs of the converter, two DC capacitor stacks of the same size are introduced to the system. Each of them is connected to one pole to ground $[17,19,54]$. In addition to DC capacitors, DC filters could also exist at the DC side of the transmission system for mitigating interference on the metallic telephone circuits, which could run adjacent to the DC links. The low harmonic content of currents and voltages in the VSC HVDC systems allow these filters to be small and simple [34].

\subsection{HVDC system configurations}


HVDC converters, rectifier and inverter, can be connected through DC links in different configurations. The main system configurations are (Figure 3 [33]),

- Monopolar HVDC systems (monopole with ground return, monopole with metallic return, monopole with grounded midpoint) $[17,33,55]$

- $\quad$ Back-to-back HVDC systems [17,33]

- Bipolar HVDC systems (bipole, bipole with metallic return, bipole with series-connected converters) $[17,33,55]$

- Multi-terminal HVDC systems $[17,33,55]$

Monopole, Ground return

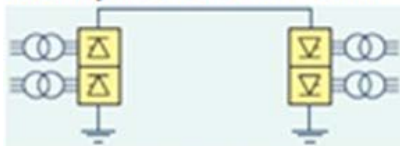

Monopole, Metallic return

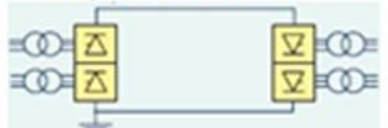

Monopole, Midpoint grounded

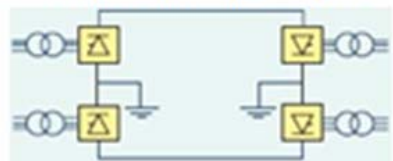

Back-to-back

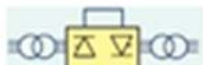

(Q) $\triangle \nabla: Q$

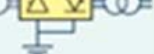

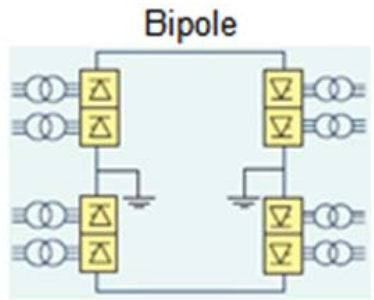

Bipole, Metallic return

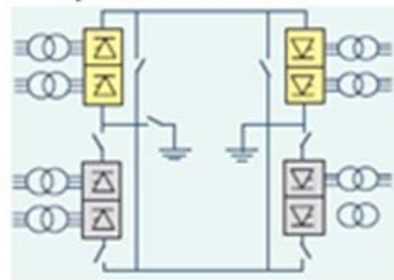

Multiterminal

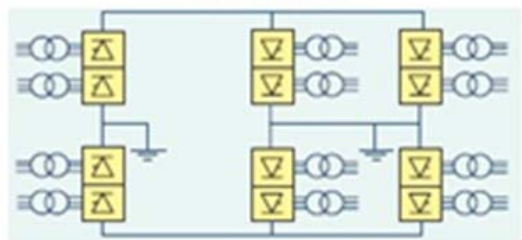

Bipole, series-connected converters

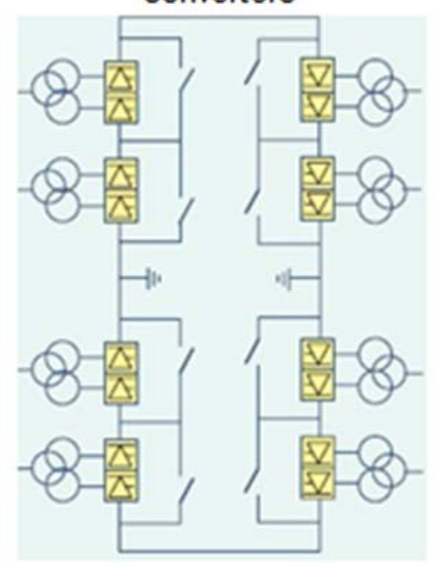

Figure 3: HVDC system topologies

\subsection{VSC HVDC multi-terminal system topologies}

Several VSC stations (multi-terminal systems) can be connected to DC buses with fixed polarity, creating DC grids similar to AC networks. These VSC HVDC grids are very attractive for wind power integration and the reinforcement of interconnected AC networks [27]. Therefore, the number of multi-terminal systems, which feed power to an AC network at different points, is increasing. As a result, the interest in studying the performance of such systems has been increasing. Many projects have investigated the potential benefits and cost-effectiveness of the multi-terminal VSC HDVC, as well as its impact on the stability of the connected AC networks and the need of the coordination of power control at the multiple DC links [56-61].

There are several different VSC HVDC multi-terminal topologies for transferring power from large offshore wind farms to the AC grid. The main topologies are [62],

- General Ring Topology (GRT): all nodes of network are connected in ring. 
- Star Topology (ST): each line from a wind farm or an onshore substation is connected to a star node.

- Star with central General Ring Topology (SGRT): a star configuration in which the central node is constructed in a ring configuration.

- Wind Farm Ring Topology (WFRT): a wind farm ring, with additional links which connect each wind farm to an onshore substation.

- Substation Ring Topology (SSRT): a ring of the onshore substations, with additional links which connect each substation to an offshore wind farm.

- Other more complex topologies as combination of the previous topologies.

[62] compares various topologies regarding several factors, such as the number of DC breakers, the ratings of lines and additional required construction. A crucial factor is the way by which the system handles a fault at a DC link. Multi-terminal systems show flexibility under fault cases, which allows isolation of the faulty part and redirection of the power flow. The selection of the optimal topology for a given application depends on the operation and robustness requirements, as well as on the geographical location of the substations and the wind farms. In general, the most appropriate topology is found to be the WFRT because it is able to meet the required flexibility with the least number of breakers and does not require an offshore platform. If shorter line lengths are required, the GRT can be attractive. However, it requires higher ratings of some lines [62].

\section{Converter control system}

This section describes the main controllers and control strategies of the converters of the VSC HVDC transmission systems. The DC voltage droop control of multi-terminal VSC HVDC grids is presented as well.

\subsection{Main controllers}

With the PWM scheme in the IGBTs of the converter, simultaneous adjustment of the magnitude and phase of the $A C$ voltage output of the converter can be achieved. This implies the capability of power control, since the active power is regulated by changing the phase of the $A C$ converter voltage, whereas the reactive power is controlled by adjusting the magnitude of the AC converter voltage $[33,34]$. The active power control loop can be set to regulate the active power flow according to the DC voltage, the frequency variation or an active power reference value. The reactive power control loop can be set to control the reactive power flow according to the AC voltage or a reactive power reference value $[33,34,63]$. The control system can also consider the converter current limitations, as determined in the inner current control function [63]. The system, as illustrated in Figure 4 [34], is a two-loop control system. The inner loop is a fast vector controller for the converter current control. The outer loop is relatively slower, including the $\mathrm{DC}$ voltage controller, the $\mathrm{AC}$ voltage controller, the active power controller, the reactive power controller and the frequency controller [17]. 


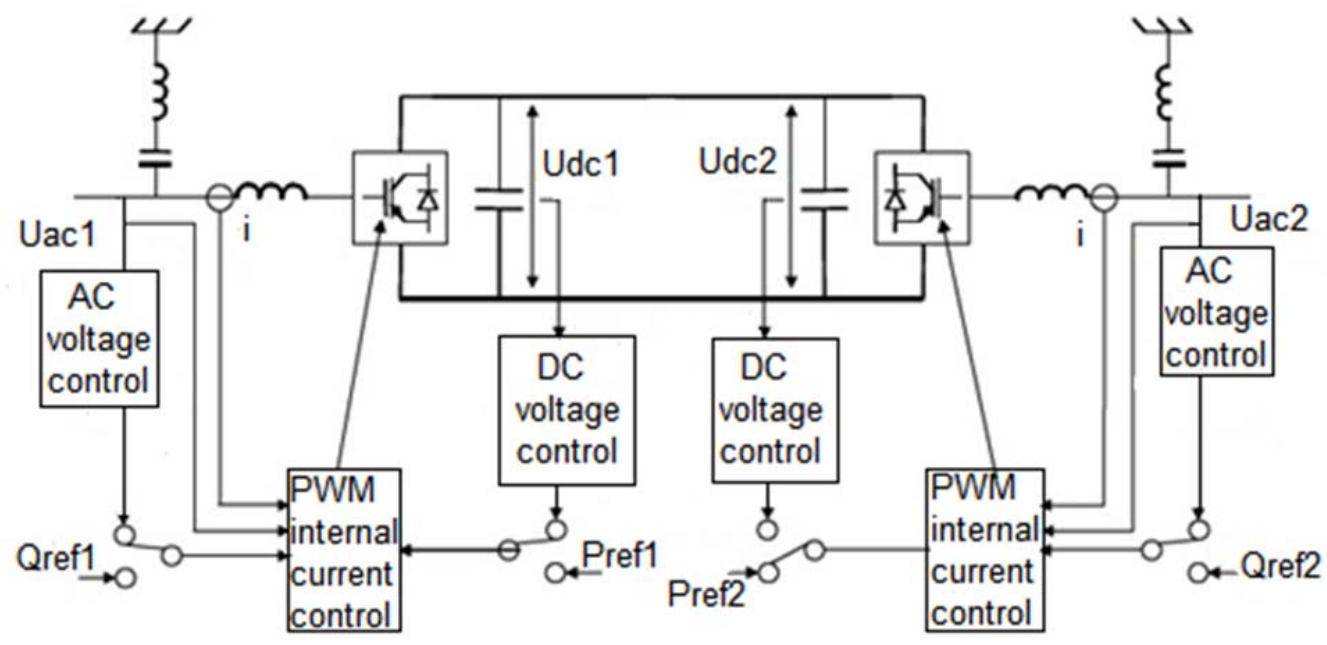

Figure 4: Control system of VSC HVDC transmission technology

\subsubsection{Inner current controller}

The aim of the inner current controller ( $\mathrm{PI}$-controller) is to take current reference values from the outer controllers and determine reference values for the terminal voltage. This control loop operates in a $d q$ rotating reference frame. The $d$-axis value of the reference current is generated by the outer controllers of the active power, the DC voltage or the grid frequency. The $q$-axis value of the reference current comes out from the outer controllers of either the AC voltage or the reactive power $[10,17]$. The $d$-axis and $q$-axis reference currents are compared to the converter's current limits, determined by its $P Q$ characteristics [10]. If the limits are exceeded, the reference currents should be decreased. The priority for limiting the d-axis or the q-axis current depends on the application [17].

In case of unbalanced voltage conditions, i.e. asymmetrical voltages, a negative sequence of quantities should be taken into account to control the operation of the converter (the zerosequence components can be assumed zero). Therefore, the inner current control loop should be divided into a positive- and a negative-sequence current controller. Reference values in daxis and q-axis should be provided for both positive- and negative-sequence currents. The reference values of the positive-sequence current are determined by the outer controllers, as described above. However, the reference currents of the negative sequence cannot be generated in a similar way. Several approaches have been proposed in literature for providing appropriate reference values of the negative-sequence current. One of the control strategies is the negative-sequence voltage compensation scheme, which aims to produce the appropriate negative-sequence currents for eliminating the negative-sequence voltages. Another approach is the control of the negative-sequence reactive current, while the reference value of the negative-sequence active current is set to be zero. This control scheme is suitable for compensating large voltage imbalances $[10,17]$. 


\subsubsection{Outer controllers}

Usually, the outer control loops (control of DC voltage, AC voltage, active power and reactive power) are implemented by PI-controllers, which regulate the corresponding quantity according to a reference value. However, other controller types have also been suggested for maintaining stability of the control scheme by the possibly simplest means $[8,10,12,17]$. Regarding the frequency regulation, [17] describes four different types of frequency controllers. The first two controllers provide a fixed reference value, while the other two are based on the relationship between active power and frequency in a power system. This relationship can be implemented by a PI-controller or a droop function.

\subsection{Control strategies}

The active and reactive power control takes place at both sides of the DC link (rectifier and inverter). However, not all controllers can be activated and used simultaneously. The selection of different control functions depends on the application. For instance, in the case of a passive load, the converter should control frequency and AC voltage, whereas in the case of a wellestablished AC system, the converter should regulate $A C$ voltage and active power flow. Nevertheless, the DC voltage control is necessary for achieving active power balance in the DC link. Therefore, one terminal of the DC link must undertake the DC voltage control, while the other should be set to control the active power or frequency. Concerning the reactive power regulation, either of the two control functions can be selected independently at both terminal of the $D C$ link, as presented in Figure $5[17,63]$.

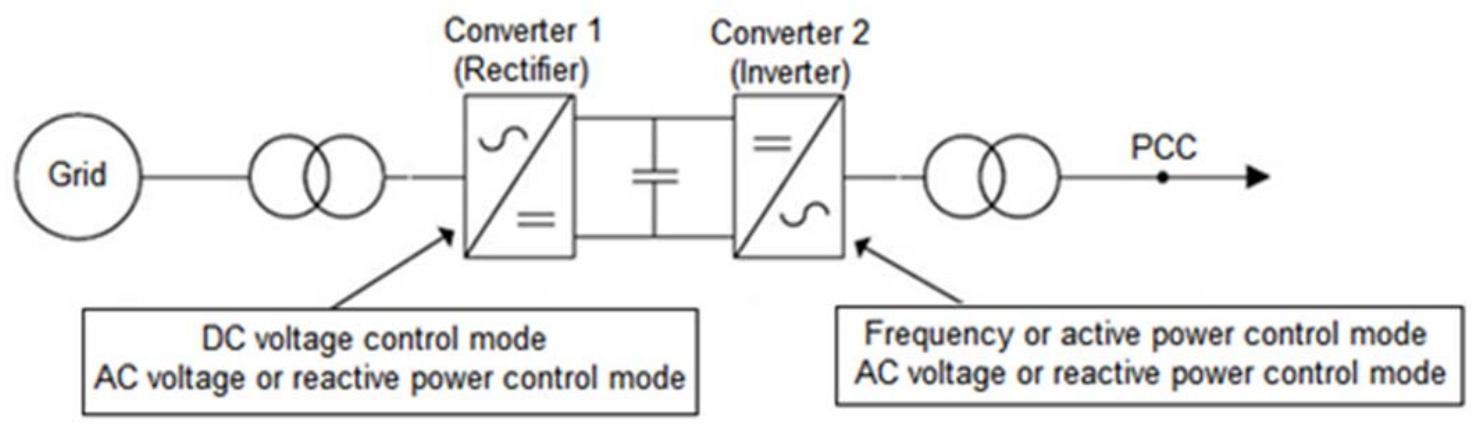

Figure 5: Control strategies in VSC HVDC transmission systems

In the case of the grid connection of an offshore wind farm, the typical converter control strategies are the following [8]:

- active and reactive power control in the converter at the wind farm side - DC voltage control and reactive power control in the converter at the grid side (Scheme 1)

- $\quad$ active power and AC voltage control in the converter at the wind farm side - DC voltage control and reactive power control in the converter at the grid side (Scheme 2)

Scheme 2 is found to be more suitable, causing lower oscillations of active and reactive power and $A C$ voltage under a fault. Therefore, instead of reactive power control, the AC 
voltage control at the wind farm side is preferred for the grid connection of offshore wind farms [8].

\subsection{DC voltage droop controller for multi-terminal systems}

In the case of multi-terminal VSC HVDC systems, various strategies of active power and DC voltage control have been proposed, such as master-slave and voltage margin control schemes [64]. A new approach has recently gained the interest of researchers for its high reliability and simple structure: the DC voltage droop control. In this control scheme, all the terminals participate in the DC voltage control and share the duty of power balancing in the DC grid, rather than trying to track their active power references. The power share of each terminal is determined by its droop constant, given by (1),

$$
\rho_{D C}=\frac{U_{D C}-U_{D C}^{r e f}}{P-P^{r e f}}
$$

where $\rho_{D C}$ is the DC voltage droop factor [64]. The converter stations with the higher values of droop will participate more in the DC voltage control and therefore their power share will be smaller $[12,64,65]$. In a fixed droop scheme, the droop factor at each terminal is calculated according to the corresponding converter ratings. However, it is desirable that the converters participate in power sharing according to not only their ratings, but also their spare capacity (headroom), i.e. the difference between the rated capacity and the present loading. For dealing with this issue, [65] suggests a modification of the initial DC voltage droop controller. In the proposed control scheme, the droop factor is a function of the available headroom of each converter. The proposed function gives higher droop factors for lower available headrooms. In this way, converters which operate very close to their operational limit (low available headroom) will not share the burden of an outage to the same extent as the converters with higher spare capacity. This approach with the variable droop factor would also be useful in the future, when the multi-terminal HVDC grids enter the power market. It will allow the owners of the converter stations to share the power mismatch appropriately, and they could use spare capacity also as ancillary service [65].

The main idea of the DC voltage droop control is to use the DC voltage as a universal indicator of DC grid loading, as the frequency is used in AC systems. In AC systems, active power-frequency droop is used in the governor control loop, for avoiding conflicts in reference values of frequency. In a similar way, in the DC grids, the active power-DC voltage droop can be used to modify the reference values of the DC voltage, for avoiding conflicting DC voltage set values at the terminals [65]. According to [64], proper calculation of the initial reference values (before their modification according to droop factor) is needed for a more precise control scheme.

\section{Capabilities of VSC HVDC transmission systems and benefits for wind farms and Transmission System Operators (TSOs)}


The technical advantages of the VSC HVDC transmission systems, as well as their enhanced control systems, enable several attractive capabilities. The benefits of the provided attributes are described below.

\subsection{Active power control and frequency response capability}

Converters transmit active power to the grid by maintaining constant DC voltage. In cases of fluctuations in the wind farm's power output, the grid-side converter provides the capability to even out, within a certain limit, short dips in power generation, by injecting to the grid more power than the wind farm produces, for maintaining the power balance in the connected AC system. On the contrary, during temporary emergencies of high frequency, the grid-side converter can avoid regulating the DC voltage for power balance; instead, it can reduce the active power injection to the grid or even start absorbing active power from the network. These functionalities allow considerably faster power control and thus faster frequency response than an AC-connected wind farm can achieve. As such, the VSC HVDC system supports the frequency regulation at the grid $[1,66]$. In addition, the wind power plant converter can adjust the frequency of the wind farm network according to the frequency of the connected AC system. Thereby turbines receive signals from the converter for modifying their production following the on-line load [66].

\subsection{Reactive power control and voltage support capability}

The control of reactive power flow between the converter and the grid can be used for compensating the needs of the network in reactive power, within the ratings of the converter $[1,66]$. The reactive power control capability of the converter is used to regulate the AC voltage of the connected network. The converter adjusts its reactive current, such that the set voltage at the bus is retained. In addition, the fast switching capability of the converter and its intelligent control systems enable the transmission system to sustain faults in the AC network. The contribution to the AC voltage control can be applied at both grid and wind farm sides $[1,66,67]$. [68] analyzes the voltage support that the VSC can provide, regarding the grid configuration of its connection with the AC system (connection of the VSC and the AC system in series, in parallel or VSC HVDC connection between asynchronous systems). [69] investigates the contribution of VSC HVDC systems to the short-circuit current during a fault in the network. The influence of various factors, such as the control mode, the fault location and type, is analyzed. The fault location and type slightly affect the value of the short-circuit current, whereas the AC voltage control mode (instead of the reactive power control mode) is found to increase the shortcircuit current contribution [69].

\subsection{Fast response to disturbances}

Fast control of the converter's active and reactive power improves the dynamic performance of the system under disturbances. With such a response speed, the VSC is able to control transients and flicker, and keep the AC bus voltage constant, enhancing the transient stability of the system. Furthermore, through fast active and reactive power modulation, VSCs also provide effective damping for mitigating electromechanical oscillations [1,27,67,69,70,71]. [71] presents 
research results regarding the improvement of sub-synchronous torsional damping by VSC HVDC systems. It is concluded that the choice of active power control mode, instead of DC voltage control, is more beneficial for the damping control. $[68,72]$ suggest the combination of active and reactive power control for better damping characteristics.

\subsection{Decoupling AC systems}

The converters of the VSC HVDC transmission system decouple the grid side and the wind farm side. Hence, disturbances of the AC voltage, as well as voltage flicker, at one network will not be transferred to the other side. Moreover, the transients caused during wind farm's energization are isolated from the grid. Therefore, the power quality at both sides is improved [66].

\subsection{Black start capability}

Through active and reactive power control by the converter, the small network of the wind farm has sufficient strength in voltage and frequency and is capable of starting the wind farm and restoring the network after a blackout. It is due to the ability of the converter to instantaneously switch over to its own internal voltage and frequency reference (PWM-based self-commutation). The converter can act as an AC source for energizing a "black" system, i.e. a passive islanded network without its own generation [73]. VSC HVDC systems present several advantages regarding black start and grid restoration after blackouts. First of all, they can control the voltage easily and fast, avoiding harmful voltage dips or over-voltages. Moreover, the VSC HVDC technology can fast control the frequency of the network and keep it within acceptable values without requiring the network plants to participate in frequency control, because the converters of the transmission system are able to compensate the frequency and voltage imbalances by injecting or absorbing active and reactive power. Furthermore, possible unsuccessful energization of transformers can be avoided. Finally, transient voltage and current stresses at equipment are avoided and the restoration process can speed up [66,72-77].

\subsection{Benefits for the wind turbines}

The aforementioned capabilities imply several benefits in the design and operation of the wind turbines. These advantages are basically provided by decoupling the wind farm from the grid. The wind farm is not responsible for the grid code compliance, since this can be done by the VSC HVDC transmission system. This allows the wind turbine developers to put more efforts on cost reduction issues, the standardization of the wind turbine design, as well as the efficiency and reliability $[11,66]$.

\subsection{Benefits for the TSOs}

The main responsibility of the TSO is to identify necessary grid reinforcements to maintain short-circuit currents to acceptable levels, avoid grid "bottlenecks", and achieve voltage stability. Regarding these issues, VSC HVDC transmission systems are a viable option, due to their fast, continuous and wide-ranged reactive power control capability and their short-circuit current contribution. Moreover, these systems can contribute to avoiding grid "bottlenecks" and undesirable load-flow paths. The most important for the TSO is that a wind farm grid-connected 
through a VSC HVDC transmission system becomes comparable to a conventional power plant, since the grid-side converter can be directly connected to a control or power dispatch center [66].

\section{Grid code requirements for the grid connection of offshore wind farms through HVDC systems}

The grid connection of offshore wind farms should fulfill the grid code requirements $[78,79]$. These requirements are supplementary to the general grid code rules $[9,80,81]$. In addition, there are technical rules [82] which should be applied to power plants connected to the grid through HVDC transmission systems. All these grid codes provide technical rules and specific requirements regarding,

- The frequency range of operation and the specific duration of operation within these ranges

- The required active power controllability, with respect to frequency deviations

- The voltage range of operation and the duration of operation within these ranges

- The reactive power exchange allowed according to P/Q capabilities

- The reactive current required during grid faults

- The LVRT capability

In the case of offshore wind farms grid-connected through HVDC systems, the grid code for offshore wind farms and the corresponding for the HVDC systems should be combined. As such, the technical restrictions of wind farms are taken into consideration, but without limiting the capabilities provided by the HVDC connection system.

\section{LVRT methods for VSC HVDC grid-connected offshore wind farms}

When a fault occurs in the host power system, the $A C$ voltage at the point of common connection is reduced. Therefore, the grid-side converter will respond by injecting more active power into the grid. However, the active power capability of the converter is limited, due to the converter current limits. Besides, the injection of reactive current takes the highest priority over the injection of active current, for compensating the voltage dip. As the active power transferred from the grid-side converter to the host power system is reduced or limited, if the wind farm continues producing the same power, the excess power is accumulated in the capacitance of the HVDC transmission system and thereby the DC voltage starts rising. In order to prevent the DC voltage from exceeding its upper limit, a reduction of the wind farm production is necessary. However, the wind farm is not able to respond directly (without any external influence) to the changes in the grid, due to the AC/AC decoupling between the wind farm network and the host power system. Subsequently, if no action is taken, the HVDC system will trip and consequently the LVRT requirements are not met. In order to deal with this issue, additional control schemes are necessary $[9,10,83]$. The control methods are: 
- The connection of a DC chopper at the DC link close to the grid-side converter: The DC chopper is activated when the rise in the DC voltage exceeds a threshold value. The excess energy will be burned in the DC chopper to mitigate the DC voltage rise. The power production of the wind farm is totally uninterrupted and therefore mechanical stresses in the turbines are significantly reduced. The usage of the DC chopper can be advantageous in cases when a very fast power regulation is required. The major disadvantage of the DC chopper solution is the additional cost of the component and its practically impossible size for removing the whole amount of heat $[9,10,83,84]$.

- The use of fast communication means, for transferring the data of conditions at the grid side to the wind farm side: In this way, the wind farm receives signals to reduce its power production. Usually, the signal is in the form of active power reference, directly delivered to the control system of each individual turbine. This solution, although simple, is not reliable in long HVDC transmission systems, like these used for the grid connection of offshore wind farms, due to the increasing communication time delay with the increasing transmission distance $[9,10,74,84]$.

- The regulation of the frequency of the wind farm network by the offshore converter, as function of the DC voltage: As the DC voltage rises, the wind turbines detect a fast increase in frequency and ramp down their power reference. This method causes large and persistent DC over-voltages, since there is no means to evacuate power and therefore to decrease the DC voltage. This method also leads to some stress over wind turbines in terms of speed variations [85]. Moreover, the recovery of the power production at the wind farm, after the fault clearance, is found to be slow $[9,10,84]$.

- The use of a droop controller, acting on the DC voltage: Above a certain threshold of the DC voltage, a droop factor decreases linearly to zero. The droop gain can be applied either to the torque demand, reducing the generator torque, or to the output of the active power controller of the offshore HVDC converter, reducing the active power $[10,83]$.

- The switch-over of the DC voltage control between the two converters: The grid-side converter relinquishes the DC voltage control and its role is to limit the current. On the other hand, the converter at the wind farm side can be set to take over the DC voltage control when the DC voltage exceeds a pre-defined threshold. In this way, a smooth transition during the exchange of DC voltage control between the two converters is ensured. The reduction of the power production of the wind farm can be achieved as described in the two previous methods. When the fault is cleared, the DC voltage decrease is monitored by the converters, which switch their control modes back to the pre-fault situation $[10,74,83]$. The DC voltage threshold should be chosen carefully; if it is set too small, it may trigger a false Fault Ride-Through (FRT) mode during other events, causing an unnecessary switch-over of the DC voltage control between the two converters [10]. 
- The regulation of the AC voltage by the offshore converter, as function of the DC voltage: The $\mathrm{DC}$ voltage rise is monitored by the offshore converter, which in response ramps down the $\mathrm{AC}$ voltage. A de-loading droop gain acts on the $\mathrm{DC}$ voltage value for determining a factor, which is introduced into the PWM of the offshore converter for properly adjusting the amplitude modulation index. Hence, when the DC voltage increases due to a fault in the AC system, the de-loading droop controller reduces the amplitude modulation index and therefore the $A C$ voltage at the offshore converter terminal $[9,10,83,84]$. An enhanced method is proposed by [84], in which machines are demagnetized in a fast and controlled way. Hence, fast voltage reduction is allowed, but high stresses to mechanical and electrical equipment are avoided. An improvement based on this method is introduced in [86]. Wind turbines equipped with full-scale converters are able to control their active and reactive power as a function of the voltage at the wind farm network. Therefore, by decreasing the AC voltage of the offshore converter, the power flow in the offshore network is impaired and the turbines cannot inject power into the wind farm grid. A switch-over of the DC voltage control between the converters at the two sides can also be applied in this method. With this method, the DC over-voltages are limited. In addition, the power flow to the terminal decreases rapidly and the power recovery after the fault clearance is faster than in the frequency control method $[9,10,83,84]$.

- The blocking of the converter valves, for limiting the current in the converter: The blocking process takes place for a temporary, pre-defined period, which is equal for all types of faults. The wind turbines are allowed to remain connected during and after the fault. In many fault conditions this strategy achieves a satisfactory reduction of overcurrents. But in cases of more severe faults, over-currents are higher and therefore longer blocking periods are required. If the applied blocking period is not long enough, over-currents are not totally avoided, leading to turbine trip-off. On the contrary, in the case of less severe faults, a longer blocking period than required can cause additional fluctuations at the connected power system [87]. For dealing with this issue, [87] proposes a variable blocking period, as function of the severity of each type of fault. Moreover, a special controller is suggested, which is activated after the de-blocking of the valves, for alleviating the oscillations at the power system caused by the blocking process. The suggested control strategy can avoid over-currents and the tripping of the turbines. Thus, it helps the system to quickly reach a steady state [87].

\section{Frequency regulation by VSC HVDC grid-connected offshore wind farms}

\subsection{Main frequency regulation strategies in VSC HVDC transmission systems}

Since the frequency of the offshore network is decoupled from the onshore grid frequency, the contribution of the wind farm to frequency regulation can only be achieved if the onshore 
grid frequency is communicated to the offshore network. In this way, the wind farm can adjust its production according to the onshore grid frequency. There are three control schemes for accomplishing this task:

- The use of DC voltage variations: The reference value of the DC voltage changes in proportion to the onshore grid frequency, i.e. if the grid frequency increases, the reference value of the DC voltage also increases. This reference value is compared to the nominal value. The error derived from the comparison is used to adjust the frequency reference of the offshore network. In this way, if there is an increase in the onshore grid frequency, the DC voltage rises and consequently the offshore network frequency is raised. The turbine converters detect this frequency increase and decrease their generation according to the droop characteristics of their frequency regulation curves $[9,88]$.

- The communication of the onshore grid frequency to the offshore HVDC converter: The offshore HVDC converter changes the frequency of the offshore network according to the grid frequency. Therefore, the onshore grid frequency is directly replicated in the offshore network and, hence, change in the DC voltage is not needed. The frequency of the offshore network is monitored by the turbine converters, which adjust their production [9].

- The communication of the onshore grid frequency directly to the turbine converters: Turbine converters regulate their production according to the onshore grid frequency. Therefore, no change in the DC voltage or the offshore network frequency is required. This is the most suitable method, as the only delay is caused by the communication process, without delays for calculations. It requires, of course, a reliable communication frame available, as the previous strategy [9].

\subsection{Frequency regulation strategies in multi-terminal VSC HVDC transmission systems}

The autonomous droop control presented in Section 3.3 leads to inappropriate frequency deviations in different AC systems. The system does not participate in reducing the frequency deviation in the case of a disturbance, since there is no change in the net power exchange with the concerned AC system. Consequently, the frequency support cannot be appropriately shared among the $A C$ grids which are interconnected through the multi-terminal VSC HVDC transmission system. Moreover, the power sharing amongst the converter stations, following a converter loss, might result in higher frequency deviations in some AC power systems, depending on the number of stations that are connected to each AC system and the governor droop coefficients of different AC grids. In addition, the autonomous power sharing takes place only between the converters in the affected pole, i.e. in the pole where the lost converter was connected. The converters in the other pole will continue operating at their pre-contingency conditions and therefore do not participate in power sharing. This means that frequency deviation in some AC power systems could be large [89]. 
For dealing with these issues, the standard autonomous power sharing control scheme is modified with the introduction of a frequency droop control loop: the power reference of the converter is adjusted by a supplementary frequency droop control, as denoted by (2),

$$
U_{D C}=U_{D C}^{r e f}+\rho_{D C} \cdot\left[P-P^{r e f}-\rho_{f} \cdot\left(f^{r e f}-f\right)\right]
$$

where $\rho_{D C}$ is the DC voltage droop factor and $\rho_{f}$ is the frequency droop factor [89]. In the case of frequency decrease (increase), the active power injected to the AC system should be increased (decreased), by changing the power reference accordingly. It should be noted that, with the modified control scheme, converters at both poles participate in frequency support. The improved control scheme in the multi-terminal VSC HVDC transmission systems is found to be effective in reducing the frequency deviation in the connected $A C$ systems following disturbances at both AC and DC sides [89].

\section{Conclusions}

The VSC HVDC transmission technology has become a technically and economically feasible grid connection solution for offshore wind power integration. This paper provides a review of the state-of-the-art VSC HVDC technology and its application for integrating large and remote offshore wind farms.

The development and functionality of VSC HVDC system's components are presented. As the core module, the VSC performs the energy conversion between AC and DC systems. Various converter topologies are briefly described. Through comparison, the MMC is considered as the most promising converter technology for VSC HVDC system.

Compared to two-terminal VSC HVDC system, multi-terminal VSC HVDC systems can provide additional controllability in transmission system and have gained more interest. Among different topologies of multi-terminal VSC HVDC, the WFRT is found to be the most attractive one.

Various converter controllers have been proposed. The control strategies are dependent on the application. It has been found that instead of reactive power control, AC voltage control is preferred for the offshore wind farm integration.

Due to the technical features and enhanced control system, VSC HVDC systems provide benefits to wind turbine manufactures, wind farm developers and TSOs.

The grid code requirements for VSC HVDC connected offshore wind farms are discussed. The focus is given on the control methods of the VSC HVDC connected offshore wind power plants for fulfilling the LVRT and frequency regulation support requirements. Due to the decoupling between the wind farm and the AC grid, how to efficiently communicate between both sides is the main challenge.

\section{References}


[1] Ackermann T, editor. Wind power in power systems. Chichester (West Sussex): John Wiley \& Sons, Ltd; 2005.

[2] Arrillaga J. High voltage direct current transmission. 2nd ed. London: The Institution of Electrical Engineers; 1998.

[3] Fink DG, Beaty HW. Standard handbook for electrical engineers. 14th ed. New York: McGraw-Hill, Inc.; 1999.

[4] Kimbark EW. Direct current transmission. New York: Wiley Interscience; 1971.

[5] Kundur P. Power system stability and control. New York: McGraw-Hill, Inc.; 1994.

[6] Larruskain DM, Zamora I, Mazón AJ, Abarrategui O, Monasterio J. Transmission and distribution networks: AC versus DC [Internet]. Cairo: Egyptian Solar Research Center; 2005. Available from http://www.solarec-egypt.com/publications.html.

[7] Agap A, Dragan CM. Multi-terminal DC connection for offshore wind farms [dissertation]. Aalborg: Aalborg University; 2009.

[8] Kong D. Advanced HVDC systems for renewable energy integration and power transmission: modelling and control for power system transient stability [dissertation]. Birmingham: University of Birmingham; 2013.

[9] Chaudhary SK. Control and protection of wind power plants with VSC-HVDC connection [dissertation]. Aalborg: Aalborg University; 2011.

[10] Sharma R. Electrical structure of future off-shore wind power plant with a high voltage direct current power transmission [dissertation]. Kgs. Lyngby: Technical University of Denmark; 2011.

[11] Xue Y, Akhmatov V. Grid-connection of large offshore windfarms utilizing VSC-HVDC: modelling and grid impact. Wind Eng. 2009;33:417-32.

[12] Uría MB. Operation and control of multi-terminal DC (MTDC) grids [dissertation]. Aalborg: Aalborg University; 2013. [13] Elliot D, Bell KRW, Finney SJ, Adapa R, Brozio C, Yu J, Hussain K. A comparison of AC and HVDC options for the connection of offshore wind generation in Great Britain. IEEE Trans Power Del. DOI: 10.1109/TPWRD.2015.2453233.

[14] Wyckmans M. Innovation in the market: HVDC LIGHT, the new technology. In: Proceedings of Distribution 2003: 7th International Energy Transmission \& Distribution Conferenece \& Exhibition. Port Melbourne, Vic.: Waldron Smith Management; 2003. p. 569-78.

[15] Heyman O, Weimers L, Bohl M-L. HVDC - a key solution in future transmission systems [Internet]. ABB, 2010. Available from http://www.abb.com/hvdc.

[16] Siemens AG, Energy Sector, Power Transmission Division. High voltage direct current transmission - proven technology for power exchange [Internet]. Siemens AG 2011. Available from http://www.energy.siemens.com/hq/en/power-transmission/hvdc.

[17] Du C. VSC-HVDC for Industrial Power Systems [dissertation]. Göteborg: Chalmers University of Technology; 2007. 
[18] Flisberg G, Carlsson C-G, Moni RS, Boveri AB. Global trends in bulk power transmission [Internet]. ABB 2003. Available from http://www.abb.com/hvdc.

[19] Grünbaum R, Halvarsson B, Wilk-Wilczynski A. FACTS and HVDC LIGHT for power system interconnections [Internet]. ABB 2003. Available from http://www.abb.com/hvdc.

[20] Lescale VF. Modern HVDC: state of the art and development trends. In: Proceedings of POWERCON '98, International Conference on Power System Technology; 1998 Aug 1821; Beijing, China. IEEE Xplore; 1998. p. 446-50.

[21] Chokhawala R, Danielsson B, Ängquist L. Power semiconductors in transmission and distribution applications. In: Proceedings of the 13th International Symposium on Power Semiconductor Devices and ICs ISPSD; 2001 Jun 4-7; Osaka, Canada. IEEE Xplore; 2001. p. 3-10.

[22] Jonsson T. Evaluation of Classical , CCC and TCSC converter schemes for long cable projects [Internet]. ABB 2003. Available from http://www.abb.com/hvdc.

[23] Persson A, Carlsson L, Åberg M. New technologies in HVDC converter design [Internet]. ABB 2003. Available from http://www.abb.com/hvdc.

[24] Fischer P, Ängquist L, Nee HP. A new control scheme for an HVDC transmission link with capacitor-commutated converters having the inverter operating with constant alternating voltage [Internet]. ABB 2012. Available from http://www.abb.com/hvdc.

[25] Carlsson L, Flisberg G, Weimers L. Recent evolution in classic HVDC [Internet]. ABB 2003. Available from http://www.abb.com/hvdc.

[26] Gunnarsson S, Jiang L, Petersson A. Active filters in HVDC transmissions [Internet]. ABB 2005. Available from http://www.abb.com/hvdc.

[27] Pan JPJ, Nuqui R, Srivastava K, Jonsson T, Holmberg P, Hafner Y-J. AC grid with embedded VSC-HVDC for secure and efficient power delivery. In: Proceedings of ENERGY 2008, IEEE Energy 2030 Conference; 2008 Nov 17-18; Atlanta (GA), USA. IEEE Xplore; 2008. p. 1-6.

[28] Carlsson L. HVDC, a "firewall" against disturbances in high-voltage grids [Internet]. ABB 2008. Available from http://www.abb.com/hvdc.

[29] Saksvik O. HVDC technology and smart grid. In: Proceedings of APSCOM 2012, 9th IET International Conference on Advances in Power System Control, Operation and Management; 2012 Nov 18-21; Hong Kong, China. Stevenage (U.K): Institution of Engineering and Technology; 2012. p. 311-17.

[30] Bittencourt S, Boveri AB, Eriksson K, Biledt G. HVDC LIGHT for electric power transmission in a deregulated market [Internet]. ABB 2003. Available from http://www.abb.com/hvdc.

[31] Asplund AG. $800 \mathrm{kV} \mathrm{HVDC} \mathrm{-} \mathrm{alternative} \mathrm{scenarios} \mathrm{for} \mathrm{long} \mathrm{distance} \mathrm{bulk} \mathrm{power}$ transmission [Internet]. ABB 2009. Available from http://www.abb.com/hvdc.

[32] Weimers L. HVDC LIGHT - a new technology for a better environment. IEEE Power Eng Rev. 1998;18:19-20. 
[33] Bahrman MP, Johnson BK. The ABCs of HVDC transmission technology. IEEE Power Energy Mag. 2007;5:32-44.

[34] Bahrman MP, Johansson JG, Nilsson BA. Voltage source converter transmission technologies - the right fit for the application. In: Proceedings of IEEE Power Engineering Society General Meeting; 2003 Jul 13-17. IEEE Xplore; 2003.

[35] Asplund G. HVDC using voltage source converters - a new way to build highly controllable and compact HVDC substations [Internet]. ABB 2003. Available from http://www.abb.com/hvdc.

[36] Lesnicar A, Marquardt R. An innovative modular multilevel converter topology suitable for a wide power range. In: Proceedings of 2003 IEEE Bologna PowerTech Conference; 2003 Jun 23-26; Bologna, Italy. IEEE Xplore; 2003.

[37] Hassanpoor A, Ilves K, Norrga S, Ängquist L, Nee H-P. Tolerance band modulation methods for modular multilevel converters [Internet]. ABB 2013. Available from http://www.abb.com/hvdc.

[38] Davies M, Dommaschk M, Dorn J, Lang J, Retzmann D, Soerangr D. HVDC PLUS basics and principle of operation [Internet]. Siemens AG 2011. Available from http://www.energy.siemens.com/hq/en/power-transmission/hvdc.

[39] Meier S. System aspects and modulation strategies of an HVDC-based converter system for wind farms [dissertation]. Stockholm: Royal Institute of Technology; 2009.

[40] Jacobson B, Karlsson P, Asplund G, Harnefors L, Jonsson T. VSC-HVDC transmission with cascaded two-level converters [Internet]. ABB 2011. Available from http://www.abb.com/hvdc.

[41] Mahimkar N, Persson G, Westerlind C. HVDC technology for large scale offshore wind connections [Internet]. ABB 2013. Available from http://www.abb.com/hvdc.

[42] Nami A, Wang L, Dijkhuizen F. Five level cross connected cell for cascaded converters [Internet]. ABB 2013. Available from http://www.abb.com/hvdc.

[43] Dijkhuizen F. Multilevel converters: review, form, function and motivation [Internet]. ABB 2012. Available from http://www.abb.com/hvdc.

[44] Vidal-Albalate R, Beltran $\mathrm{H}$, Rolan A, Belenguer E. Analysis of the performance of MMC under fault conditions in HVDC-based off-shore wind farms. IEEE Trans Power Del. DOI: 10.1109/TPWRD.2015.2468171.

[45] Dodds S, Railing B, Akman K, Jacobson B, Worzyk T, Nilsson B. HVDC VSC (HVDC LIGHT) transmission - operating experiences [Internet]. ABB 2011. Available from http://www.abb.com/hvdc.

[46] Eriksson K. HVDC LIGHT and development of voltage source converters [Internet]. ABB 2003. Available from http://www.abb.com/hvdc.

[47] Jacobson B, Jiang-Häfner $Y$, Rey P, Asplund G, Jeroense M, Gustafsson A, et al. HVDC with voltage source converters and extruded cables for up to $\pm 300 \mathrm{kV}$ and $1000 \mathrm{MW}$ [Internet]. ABB 2008. Available from http://www.abb.com/hvdc. 
[48] Asplund G, Eriksson K, Tollerz O. Land and sea cable interconnections with HVDC LIGHT [Internet]. ABB 2008. Available from http://www.abb.com/hvdc.

[49] Johannesson K, Gustafsson A, Karlstrand J, Jeroense M. HVDC LIGHT cables for long distance grid connection [Internet]. ABB 2009. Available from http://www.abb.com/hvdc.

[50] Koldby E, Hyttinen M. Challenges on the road to an offshore HVDC grid [Internet]. ABB 2009. Available from http://www.abb.com/hvdc.

[51] Häfner J, Jacobson B. Proactive hybrid HVDC breakers - a key innovation for reliable HVDC grids [Internet]. ABB 2011. Available from http://www.abb.com/hvdc.

[52] Callavik M. HVDC grids for offshore and onshore transmission [Internet]. ABB 2011. Available from http://www.abb.com/hvdc.

[53] Callavik M, Blomberg A, Häfner J, Jacobson B. Breakthrough! ABB's hybrid HVDC breaker, an innovation breakthrough enabling reliable HVDC grids [Internet]. ABB 2013. Available from http://www.abb.com/hvdc.

[54] Asplund G, Eriksson K, Svensson K. DC transmission based on voltage source converters [Internet]. ABB 2003. Available from http://www.abb.com/hvdc.

[55] Sellick RL, Åkerberg M. Comparison of HVDC LIGHT (VSC) and HVDC CLASSIC (LCC) site aspects, for a $500 \mathrm{MW} 400 \mathrm{kV}$ HVDC transmission scheme. In: Proceedings of ACDC 2012 10th IET International Conference on AC and DC Power Transmission; 2012 Dec 4-5; Birmingham, UK. Stevenage (UK): Institution of Engineering and Technology; 2012. p. 63-9.

[56] Eriksson R. Coordinated control of HVDC links in transmission systems [dissertation]. Stockholm: Royal Institute of Technology; 2011.

[57] Saxena KM, Bhatele RP, Channakeshava, Murty ASR, Prasad M, Carlsson C-G, et al. HVDC multi-terminal interconnections - a viable and optimal solution for India [Internet]. ABB 2003. Available from http://www.abb.com/hvdc.

[58] Fischer de Toledo P, Asplund G, Jansson E. Aspects on infeed of multiple HVDC into one AC network [Internet]. ABB 2012. Available from http://www.abb.com/hvdc.

[59] Andersson G, Fischer de Toledo P, Liss G. HVDC multi-infeed performance [Internet]. ABB 2003. Available from http://www.abb.com/hvdc.

[60] Fischer de Toledo P, Bergdahl B, Asplund G. Multiple infeed short circuit ratio - aspects related to multiple HVDC into one AC network. In: Proceedings of 2005 IEEE/PES Transmission and Distribution Conference and Exhibition: Asia and Pacific; 2005 Aug 18. IEEE Xplore; 2005. p. 1-6.

[61] Preece R, Milanovic JV. Tuning of a damping controller for multi-terminal VSCHVDC grids using the probabilistic collocation method. IEEE Trans Power Del. 2014;29:318-326.

[62] Gomis-Bellmunt O, Liang J, Ekanayake J, King R, Jenkins N. Topologies of multi-terminal HVDC-VSC transmission for large offshore wind farms. Electr Power Syst Res. 2011;81:271-81. 
[63] Pan J, Nuqui R, Tang L, Holmberg P. VSC-HVDC control and application in meshed AC networks [Internet]. ABB 2009. Available from http://www.abb.com/hvdc.

[64] Haileselassie TM, Uhlen K. Precise control of power flow in multi-terminal VSC-HVDCs using DC voltage droop control. In: Proceedings of 2012 IEEE Power and Energy Society General Meeting; 2012 Jul 22-26; San Diego (CA), USA. IEEE Xplore; 2012. p. 1-9.

[65] Chaudhuri NR, Chaudhuri B. Adaptive droop control for effective power sharing in multiterminal DC (MTDC) grids. IEEE Trans Power Syst. 2013;28:21-9.

[66] Jiang-Häfner Y, Ottersten R. HVDC with voltage source converters - a desirable solution for connecting renewable energies [Internet]. ABB 2010. Available from http://www.abb.com/hvdc.

[67] Zhang L, Harnefors L, Rey P. Power system reliability and transfer capability improvement by VSC-HVDC (HVDC LIGHT) [Internet]. ABB 2008. Available from http://www.abb.com/hvdc.

[68] Johansson SG, Asplund G, Jansson E, Rudervall R. Power system stability benefits with VSC DC-transmission systems [Internet]. ABB 2008. Available from http://www.abb.com/hvdc.

[69] Jiang-Häfner $Y$, Hyttinen $M$, Pääjärvi B. On the short circuit current contribution of HVDC LIGHT. In: Proceedings of 2002 IEEE/PES Transmission and Distribution Conference and Exhibition Asia Pacific; 2002 Oct 6-10. IEEE Xplore; 2002. p. 1926-32.

[70] Eriksson K, Liljegren C, Sobrink K. HVDC LIGHT experiences applicable for power transmission from offshore wind power parks [Internet]. ABB 2008. Available from http://www.abb.com/hvdc.

[71] Jiang-Häfner $Y$, Duchén $H$, Lindén $K$, Hyttinen $M$, Fischer de Toledo $P$, Tulkiewicz $T$, et al. Improvement of subsynchronous torsional damping using VSC HVDC [Internet]. ABB 2003. Available from http://www.abb.com/hvdc.

[72] Papadopoulos C, Papageorgiou P, Stendius L, Åström J, Hyttinen M, Johansson S. Interconnection of Greek islands with dispersed generation via HVDC LIGHT technology [Internet]. ABB 2008. Available from http://www.abb.com/hvdc.

[73] Wang P, Zhang XP, Covertry PF, Zhang R. Start-up control of an offshore integrated MMC multi-terminal HVDC system with reduced DC voltage. IEEE Trans Power Syst. DOI: 10.1109/TPWRS.2015.2466600.

[74] Xu L, Andersen BR. Grid connection of large offshore wind farms using HVDC. Wind Energy. 2006;9:371-82.

[75] Jiang-Hafner Y, Duchen H, Karlsson M. Ronstrom L, Abrahamsson B. HVDC with voltage source converters - a powerful standby black start facility. In: Proceedings of 2008 T\&D IEEE PES Transmission and Distribution Conference and Exposition; 2008 Apr 21-24; Chicago, USA. IEEE Xplore; 2008. p. 1-9.

[76] Vestergaard O, Westman B, McKay G, Jones P, Fitzgerald J, Williams B. HVDC enabling the transition to an energy system based on renewables. In: Proceedings of ACDC 2010 9th IET International Conference on AC and DC Power Transmission; 2010 Oct 19-21; London, UK. IEEE Xplore; 2010. p. 1-6. 
[77] Sandeberg $P$, Stendius L. Large scale offshore wind power energy evacuation by HVDC LIGHT [Internet]. ABB 2008. Available from http://www.abb.com/hvdc.

[78] E.ON Netz GmbH. Requirements for offshore grid connections in the E.ON Netz network. E.ON Netz grid code report. Bayreuth: E.ON Netz GmbH; 2008 Apr.

[79] TenneT TSO GmbH. Requirements for offshore grid connections in the grid of TenneT TSO GmbH. TenneT TSO grid code report. Bayreuth: TenneT TSO GmbH; 2010 Oct.

[80] E.ON Netz GmbH. Grid connection regulations for high and extra high voltage. E.ON Netz grid code report. Bayreuth: E.ON Netz GmbH; 2006 Apr.

[81] Eltra/Elkraft. Wind turbines connected to grids with voltages above $100 \mathrm{kV}$. Technical regulation TF 3.2.5. Elkraft System and Eltra \& Danish Energy Authority; 2004 Nov-Dec.

[82] ENTSO-E. ENTSO-E draft network code on HVDC connections and DC-connected power park modules. Grid code technical report. ENTSO-E; 2013 Sep.

[83] Ramtharan G, Arulampalam A, Ekanayake JB, Hughes FM, Jenkins N. Fault ride through of fully rated converter wind turbines with $\mathrm{AC}$ and $\mathrm{DC}$ transmission systems. IET Renew Power Gener. 2009;3:426-38.

[84] Feltes C, Wrede H, Koch FW, Erlich I. Enhanced fault ride-through method for wind farms connected to the grid through VSC-based HVDC transmission. IEEE Trans Power Syst. 2009;24:1537-46.

[85] Silva B, Moreira, CL, Leite H, Lopes JAP. Control strategies for AC fault ride through in multi-terminal HVDC grids. IEEE Trans Power Del. 2014;29:395-405.

[86] Erlich I, Feltes C, Shewarega F. Enhanced voltage drop control by VSC-HVDC systems for improving wind farm fault ride through capability. IEEE Trans Power Del. 2014;29:378385.

[87] Vrionis TD, Koutiva XI, Vovos NA, Giannakopoulos GB. Control of an HVdc link connecting a wind farm to the grid for fault ride-through enhancement. IEEE Trans Power Syst. 2007;22:2039-47.

[88] Liu H, Chen Z. Contribution of VSC-HVDC to frequency regulation of power systems with offshore wind generation. IEEE Trans Energy Conv. 2015;30:918-926.

[89] Chaudhuri NR, Majumder R, Chaudhuri B. System frequency support through multiterminal DC (MTDC) grids. IEEE Trans Power Syst. 2013;28:347-56. 